Prof. Dr. med. Gian Domenico Borasio

Lehrstuhl für Palliativmedizin

Centre Hospitalier Universitaire Vaudois (CHUV)

Universität Lausanne, Schweiz
Entscheidungen am Lebensende

29 - Aktuelle Rechtslage

31 - Demenz und Wachkoma

35 - Todkranke Kinder

\title{
Entscheidungen am Lebensende
}

\section{Der Hausarzt spielt eine zentrale Rolle}

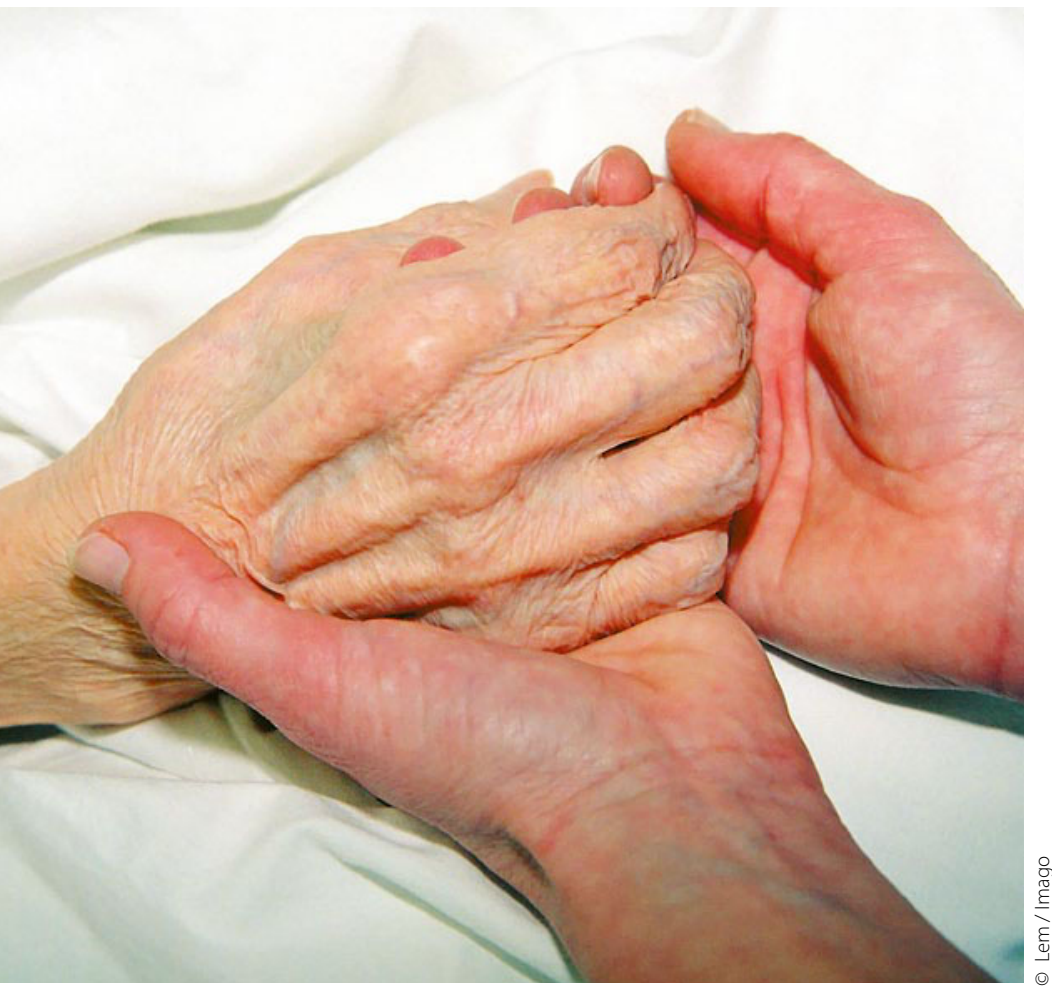

- Zu den schwierigsten Situationen in der Medizin gehören die Entscheidungen über lebensverlängernde Maßnahmen bei schwerkranken und/oder hochbetagten Patienten. Diese Aufgabe ist für uns Ärzte umso belastender, da wir im Studium nie richtig darauf vorbereitet wurden. Eine wichtige Hilfestellung leistet nun das neue Gesetz zur Patientenverfügung. Dieses legt in $§ 1901$ b Absatz 1 fest: "Der behandelnde Arzt prüft, welche ärztliche Maßnahme im Hinblick auf den Gesamtzustand und die Prognose des Patienten indiziert ist. Er und der Betreuer erörtern diese Maßnahme unter Berücksichtigung des Patientenwillens als Grundlage für die nach $\S 1901$ a zu treffende Entscheidung."
Das bedeutet, dass dem Arzt in diesem Entscheidungsprozess eine doppelte Aufgabe zukommt: Erstens hat er in eigener Verantwortung die Indikation für die infrage kommende ärztliche Maßnahme zu prüfen. Die Bedeutung dieser Aufgabe wird von Ärzten oft unterschätzt. Das ist bedauerlich, denn Entscheidungen auf der Grundlage der ärztlichen Indikation können Schuldgefühle und das Risiko von pathologischen Trauerverläufen bei den Angehörigen mindern. Leider wird der Indikationsstellung in der ärztlichen Ausbildung wenig Bedeutung beigemessen, obwohl sie Voraussetzung für die Durchführung jeder diagnostischen und therapeutischen Maßnahme ist.

Zweitens hat der Arzt nach dem neuen Gesetz einen eigenen Prüfauftrag in Bezug auf den Patientenwillen. Er ist somit kein einfacher Erfüllungsgehilfe des Betreuers/Bevollmächtigten: Bei begründetem Zweifel an dessen Auslegung des Patientenwillens kann und muss der Arzt das Betreuungsgericht einschalten. Dadurch sollen Patienten vor einer einseitigen Auslegung ihres vorausverfügten oder mutmaßlichen Willens geschützt werden - ein wichtiger Beitrag zur Fürsorge.

\section{Unterstützen Sie Ihre Patienten schon im Vorfeld}

Dem Hausarzt kommt bei Entscheidungen am Lebensende eine zentrale Rolle zu, und zwar hinsichtlich der Prävention von Auslegungskonflikten: Auch wenn das Gesetz eine ärztliche Beratung nicht zwingend vorsieht, ist eine Beratung durch den Hausarzt bei der Erstellung einer Patientenverfügung dringend zu empfehlen. Sie schützt zum einen den Verfasser vor späteren Zweifeln an seiner Einwilligungsfähigkeit; zum anderen ermöglicht sie den Ärzten, welche die Patientenverfügung umsetzen müssen, bei Auslegungszweifeln sich direkt mit dem Hausarzt in Verbindung zu setzen und eine unschätzbare Unterstützung zu erfahren. Und nicht zuletzt sind die Hausärzte (die ohnehin die Hauptlast der Palliativversorgung tragen) diejenigen, die die Patienten rechtzeitig auf die Sinnhaftigkeit der Erstellung einer Vorsorgevollmacht, am besten in Kombination mit einer Patientenverfügung, hinweisen können. Auch bei Entscheidungen am Lebensende gilt: Prävention ist besser als Therapie. 